\title{
Using the Work System Method with Freshman Information Systems Students
}

\author{
Jan Recker \\ Queensland University of \\ Technology, \\ Brisbane, QLD, Australia
}

j.recker@qut.edu.au

\author{
Steven Alter \\ University of San \\ Francisco, \\ San Francisco, CA, USA
}

alter@usfca.edu

\section{Executive Summary}

Recent surveys of information technology management professionals show that understanding business domains in terms of business productivity and cost reduction potential, knowledge of different vertical industry segments and their information requirements, understanding of business processes and client-facing skills are more critical for Information Systems personnel than ever before. In an attempt to restructure the information systems curriculum accordingly, our view is that information systems students need to develop an appreciation for organizational work systems in order to understand the operation and significance of information systems within such work systems.

Work systems are systems in which human participants and/or machines perform work to produce products and/or services for internal or external customers. This view stresses that systems in organizations involve more than an IT system (such as a data warehouse or an accounting application). The work system method has been designed to assist in developing an understanding of work systems in organizations. The method describes an adaptable set of steps that an analyst can use to identify a work system, clarify problems, issues, and opportunities related to that work system, identify possible directions for change, and produce and justify a recommendation.

To date, the use of the work system method in information systems curricula has demonstrated that postgraduate students can benefit from this approach when examining a business situation involving an information system. To contrast the experiences of post-graduate students with work experiences, in this paper we report on use of a simplified version of the Work System Method in a freshman Information Systems course and study how students without work or technical knowledge performed when analyzing IT-reliant work systems in business settings. We reflect on an introductory information systems course that included a work system analysis assignment, and we examine the reports produced by students as well as the learning outcomes and challenges.

Material published as part of this publication, either on-line or in print, is copyrighted by the Informing Science Institute. Permission to make digital or paper copy of part or all of these works for personal or classroom use is granted without fee provided that the copies are not made or distributed for profit or commercial advantage AND that copies 1) bear this notice in full and 2) give the full citation on the first page. It is permissible to abstract these works so long as credit is given. To copy in all other cases or to republish or to post on a server or to redistribute to lists requires specific permission and payment of a fee. Contact Publisher@InformingScience.org to request redistribution permission.
Our analysis reveals that undergraduates can benefit from analyzing IT-reliant work systems through the work system method. Their analyses tend to reflect their lack of business background, but doing these analyses can help as a first step toward appreciating the business situations in which information systems are used. We present a series of implications for improving the class experience related to teaching work system ideas 
and including IT-reliant work systems as an essential part of an introductory information systems course. These implications relate to clarifying the scope of a work system analysis, providing examples of successful as well as unsuccessful analyses for guidance, providing relevant analysis templates, succinctly defining terminology and assisting in emphasizing the differences between technologies, work systems, and organizations. Perusing these recommendations, our work demonstrates how information systems students can start developing a holistic understanding of information technology in use in corporate organizations at a very early stage of their learning process.

Keywords: Information system education, introductory information system course, work system, work system method.

\section{Introduction}

Universities in many countries have been reviewing their curriculums to ensure that students are offered degrees that will equip them well for life in a world of global forces and rapid change. Many of these curriculum changes recognize the importance of information technology and the challenges of "information technology in use in a modern world" (Miliszewska, Venables, \& Tan, 2010), which is the core application field of the information systems (IS) discipline (R. J. Paul, 2010).

In examining the key skills that IS graduates should posses in order to cope with the importance of IT in today's world, the latest ACM and AIS model curriculum posits the following essential capabilities to be developed in IS graduates (Topi et al., 2010):

- Improving organizational processes,

- Exploiting opportunities created by technology innovations,

- Understanding and addressing information requirements,

- Designing and managing enterprise architecture,

- Identifying and evaluating solution and sourcing alternatives,

- Securing data and infrastructure, and

- Understanding, managing and controlling IT risks.

Several of these capabilities have been examined closely in education literature, for example, in reflections on teaching database security (Murray, 2010) or web technology (Zhang \& Olfman, 2010).

These and related pedagogical articles have in common that they pertain most closely to students in the midst (e.g., Kamoun \& Selim, 2007; Murray, 2010) or even towards the end of their coursework program (e.g., Hunsinger \& Smith, 2008; Venables \& Tan, 2009). Limited attention to date, however, has been given to undergraduate introductory courses at the very beginning of a university program.

Undergraduate introductory information system courses at the beginning of a curriculum present a difficult pedagogical challenge because undergraduate students often have limited backgrounds in business (Firth, Lawrence, \& Looney, 2008). If undergraduate IS courses focus primarily on computer applications such as Microsoft Word and Excel, they are not really IS courses, and in many cases simply repeat material that undergraduate students have learned in high school or other college courses. If those courses are basically technology courses (what is a computer, what is a network, what is a database) they still are not really IS courses and often seem unnecessary to the more tech-savvy students who have already used computers, the Internet, social networking, and wireless technologies. If those courses focus on types of information systems and on processes of building information systems, there are serious questions about whether the core subject matter will be meaningful to students with little business experience, whether it can be mastered 
at a level beyond "memorize and repeat," and whether such courses provide a strong introduction to relevant topics such as infrastructure, organization, strategy, ethics, and work practices. Recent studies of IT industry trends, such as the IT workforce study by Abraham et al. (2006) or the survey of information technology management professionals by Luftman and Zadeh (2011) confirm that understanding business domains in terms of business productivity and cost reduction potential, knowledge of different vertical industry segments and their information requirements, understanding of business processes and client-facing skills is more critical for IS personnel than ever before.

Responses to these events and changes have included several calls for new and innovative IS curricula (Albrecht, Romney, Lowry, \& Moody, 2009; Bullen, Abraham, Gallagher, Simon, \& Zwieg, 2009; Carlsson, Hedman, \& Steen, 2010; Helfert, 2008). This paper follows the call for innovation in IS curricula by focusing on curriculum design for introductory IS courses on an undergraduate level. It reports on an effort to incorporate a work system project into an introductory information system course for freshmen at a major university in Australia. In addition to covering typical introductory material such as hardware and software technologies, relevant concepts such as database and knowledge management, development methodologies, and managerial and social issues of information technology, this introductory course required teams of students to write a major paper concerning an IT-reliant work system, i.e., a system in which human participants and/or machines perform work to produce products and/or services for internal or external customers, and which relies on IT to operate (Alter, 2003, 2008). The pedagogical goal was to make sure that students would appreciate why information systems are an integral part of the work systems through which organizations operate. Achieving this goal would help them develop a holistic understanding of the importance of information systems in organizations, including relationships to business strategy, organizational and technological infrastructures, people, and everyday work practices. That type of holistic understanding, in turn, would strongly support the guiding assumptions of the latest IS model curriculum (Topi et al., 2010).

This paper proceeds as follows: It presents a brief overview of the ideas underlying work systems and the corresponding method for analyzing IT-reliant work systems. The explanation of the course setting includes descriptions of the students, the course, and the assignment related to ITreliant work systems. The analysis includes examples illustrating the types of papers that were most successful, factors that limited the success of other papers, and a qualitative examination of the learning results obtained in the course. A series of implications for teaching provides recommendations about how to use this type of assignment to make it more likely that undergraduate students with little or no business experience will nonetheless develop a basic appreciation of the essence and significance of information systems in organizations.

\section{Background}

\section{Viewing Systems as Work Systems}

The idea of viewing systems in organizations as work systems evolved iteratively through information system courses for MBA and Executive MBA students that emphasized IT-reliant work systems in organizations.

The work system method builds upon a static view of a current or proposed work system in operation, which is known as the work system framework and is shown in Figure 1. It describes nine elements that form the basis for describing and analyzing IT-reliant work systems in organizations. 
The work system framework focuses on a work system's form and operation at a point in time and is designed to emphasize business rather than IT concerns. It covers situations that might or might not have tightly defined business processes and might or might not be IT-intensive. Table 1 summarizes the key basic terms of the work system framework.

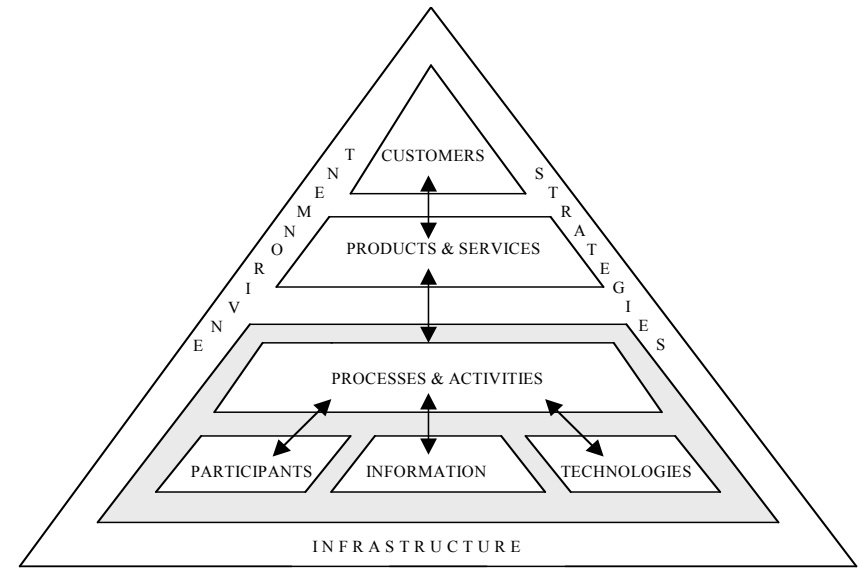

Figure 1: The Work System Framework. (Alter, 2006b), updated.

Table 1: Basic Terms Underlying the Work System Method (Alter, 2006b)

\begin{tabular}{|c|c|}
\hline Basic Term & Definition \\
\hline Work system & A view of work as occurring through a purposeful system. \\
\hline Work system framework & $\begin{array}{r}\text { A model for organizing an initial understanding of how a particular work } \\
\text { system operates and what it accomplishes. }\end{array}$ \\
\hline Customers & $\begin{array}{r}\text { Are the people who receive, use or benefit directly from products and ser- } \\
\text { vices that a work system produces. }\end{array}$ \\
\hline Products and services & $\begin{array}{l}\text { Are the combination of physical things, information, and services that the } \\
\text { work system produces for its various customers. }\end{array}$ \\
\hline Processes and activities & $\begin{array}{l}\text { Include all of the work practices within the work system, including struc- } \\
\text { tured business processes and unstructured, perhaps improved activities. }\end{array}$ \\
\hline Participants & Are people who perform the work. \\
\hline Information & $\begin{array}{r}\text { Includes codified and non-codified information used and created as partici- } \\
\text { pants perform their work. }\end{array}$ \\
\hline Technologies & Are tools that help people work more efficiently. \\
\hline
\end{tabular}

The main premises for visualizing systems in organizations as work systems are summarized next. More detailed discussions are presented in Alter (2006b, 2007, 2008). The use of the work system method as a pedagogical instrument is discussed in detail by Petkov, Petkova, Sewchurran, Andrew, \& Misra (2012).

\section{Premise No 1: Organizations operate through work systems.}

Work systems are systems in which human participants and/or machines perform work to produce products and/or services for internal or external customers. Typical examples of work systems in organizations include designing products, finding customers, selling to customers, manufacturing, products, providing services, distributing products, hiring employees, paying payroll, producing corporate plans, and so on. Table 2 lists representative examples of work systems se- 
lected and analyzed by over 300 advanced MBA students at a large public US university as part of core MBA courses between 2009 and 2011.

\begin{tabular}{|r|r|r|}
\hline \multicolumn{3}{|c|}{ Table 2: Examples of work systems analyzed by MBA students } \\
(Truex, Alter, \& Long, 2010)
\end{tabular}

\section{Premise No 2: Most work systems in organizations are IT-reliant.}

Most work systems cannot operate efficiently or effectively without the support of information systems. Developing an information system without a substantial understanding of the work system that is to be supported is a recipe for confusion and disappointment. Some of the IT-reliant work systems that are discussed in the IS field are not fully "digital" because they involve physical components (e.g., manufacturing systems, delivery systems, retailing systems). Other ITreliant work systems that are discussed in the IS field are pure information systems because they are totally devoted to processing information (e.g., Internet search, e-commerce for downloadable products). In either case, the nine elements of the work system framework reveal that an understanding of a work system involves much more than documentation of a business process' information, and technology.

\section{Premise No 3: Business professionals need to think about work systems in order to understand the operation and significance of information systems.}

The traditional IS-centric and IT-centric ways of talking about information systems are essential for programmers and programming projects but are incomplete for business professionals and for IT professionals who intend to collaborate and communicate effectively with business professionals. 


\section{Premise No 4: For business professionals, "the system" of interest is usually a work system, not just the information system that supports it.}

Since business performance is an aggregation of work system performance, business professionals should see most business information systems as a means for operating or supporting work systems. From a business viewpoint, the success of an information system is fundamentally about how well it supports the behavior of one or more work systems. Likewise, from a business viewpoint implementation means implementation of a new or improved work system, which includes changes in information systems as well as other changes that may or may not involve information systems.

\section{Premise No 5: A work system's life cycle involves iterations of planned and unplanned change.}

The various types of SDLC (systems development life cycle) models are basically project models. In contrast, a work system life cycle model (WSLC) describes how work systems evolve over time through a combination of planned change executed through projects and unplanned change that occurs through local adaptations and experimentation outside of formal projects (Alter, 2003, 2006b, 2008).

\section{Premise No 6: The work system view of systems is different from traditional systems analysis views.}

The view of "systems" in the work system approach differs from the typical view of systems in systems analysis textbooks. In the work system approach, the unit of analysis is a socio-technical work system defined as a system in which human participants and/or machines perform work using information, technology, and other resources to produce products and/or services for internal or external customers (Alter, 2006b). This view stresses that systems in organizations involve more than an IT system (such as a data warehouse or an accounting application, for example). In contrast, traditional systems analysis and design books often view the "system" only as a technical, computer-based artifact that requires architecture, components, modules, interfaces, and data. For example, in a summary of the design phase of the software development lifecycle, Hoffer, George, and Valacich (2007, p. 13) say "analysts must design all aspects of the system, from input and output screens to reports, databases, and computer processes." The work system view is therefore more encompassing as it also allows for the consideration of work systems that do not rely on information technology or computer-based systems altogether.

\section{The Work System Method}

The work system method (WSM) is designed to assist in developing an understanding of work systems in organizations. The method describes an adaptable set of steps that an analyst can use to identify a work system, clarify problems, issues, and opportunities related to that work system, identify possible directions for change, and produce and justify a recommendation. It is organized around a typical problem solving approach of defining a problem, gathering and analyzing appropriate data, and generating and selecting a preferred alternative. WSM has evolved over many years and has been described at various levels of detail, including various templates that allow deeper analysis if desired (Alter, 2006b; Petkov et al., 2012; Truex et al., 2010).

Previously, the work system method was explored as a teaching tool mostly at a postgraduate level. Many MBA and Executive MBA students, for instance, have used the work system snapshot successfully when launching discussions of work systems in their own organizations (Alter, 2006a; Truex et al., 2010). More recently, some authors have explored how the work system 
method can be used in undergraduate teaching. Ramiller (2005), for instance, describes the use of the work systems concept in an undergraduate IS course for the purpose of understanding the notion of business processes, and Petkov and Petkova $(2006,2008)$ applied it as a vehicle for improvement of student understanding of a business situation involving an IS implementation problem. In this paper, we specifically explore the application of the work system method in an introductory freshman IS course.

WSM is divided into three major steps: Step one is identifying the system problem (SP), step two is analyzing the system and identifying possible areas for improvement (AP), and step three proposes recommendations and justifications (RJ) for these changes. In this paper we emphasize the first two steps because this reduced scope reflects the boundaries set for the student reports. This limit allowed students to focus on the tasks of analyzing and improving IT-reliant systems in a holistic manner without moving too close towards technical implementation or other technical or organizational aspects of change.

Across the three steps, the WSM can be used at three levels of detail:

Level one encourages the user to think about the situation at hand in work systems terms. It provides a set of headings to encourage attention to each of the three main steps (SP, AP, and RJ) without providing further guidance.

Level two provides, for each step in the level one analysis, a set of important questions that are relevant to almost any analysis of a system in an organization, IT-reliant or not. The questions serve as a checklist to ensure comprehensiveness and completeness of any system analysis project.

Level three identifies specific topics that are worth considering when answering the questions at level two. It serves as a toolbox of topics, methods and guidelines, providing a direction for looking at frequently important topics related to the elements of the work system under analysis.

Checklists, diagrams and templates are provided to organize concepts and knowledge in an easily accessible form. In our particular teaching setting, level three was excluded from the scope of the reports, because the use of level three is optional and serves as means for a deeper analysis of the findings reported on level two.

Table 3 summarizes the steps and levels of the work system method. In Table 3, the focus of the student reports we examine in this paper are highlighted gray.

\begin{tabular}{|r|r|r|r|}
\hline \multicolumn{5}{|c|}{ Table 3: Three Levels of the Work System Method } \\
\hline & $\begin{array}{r}\text { First step in WSM } \\
\text { (System and problem) }\end{array}$ & $\begin{array}{r}\text { Second step in WSM } \\
\text { (Analysis and possibilities) }\end{array}$ & $\begin{array}{r}\text { Third step in WSM } \\
\text { (Recommendation and } \\
\text { justification) }\end{array}$ \\
\hline $\begin{array}{r}\text { Headings in } \\
\text { Level One }\end{array}$ & $\begin{array}{r}\text { Identification of the work } \\
\text { system that has the prob- } \\
\text { lems or opportunities. }\end{array}$ & $\begin{array}{r}\text { Analysis of current issues and } \\
\text { identification of possibilities } \\
\text { for improvement. }\end{array}$ & $\begin{array}{r}\text { Recommendation and its } \\
\text { justification. }\end{array}$ \\
\hline $\begin{array}{r}\text { Questions in } \\
\text { Level Two }\end{array}$ & $\begin{array}{r}\text { SP1 through SP5: } \\
\text { Five questions about the } \\
\text { system and problem. }\end{array}$ & $\begin{array}{r}\text { AP1 through AP10: } \\
\text { Ten questions related to } \\
\text { analysis and possibilities. }\end{array}$ & $\begin{array}{r}\text { Ten questions related to the } \\
\text { recommendation and its } \\
\text { justification. }\end{array}$ \\
\hline $\begin{array}{r}\text { Topics and } \\
\text { guidelines in } \\
\text { Level Three }\end{array}$ & $\begin{array}{r}\text { Checklists, Templates, } \\
\text { and Diagrams }\end{array}$ & $\begin{array}{r}\text { Checklists, Templates, and } \\
\text { Diagrams }\end{array}$ & $\begin{array}{r}\text { Checklists, Templates, and } \\
\text { Diagrams }\end{array}$ \\
\hline
\end{tabular}


As displayed in Table 3, the simplified version of WSM that was used in the teaching experience reported here focuses on identifying the work system and its main problems, issues, or opportunities, and then analyzing the work system and identifying possibilities for improvement. To make the student assignment practical in an introductory course, the assignments did not include presenting and justifying recommended changes in the work system, although students were allowed to propose improvements if they wished to do so. Appendix A summarizes the instructions the students received for applying a simplified version of WSM.

Analysis as part of the work system method typically begins with using a simple and widely applicable tool called a work system snapshot (Alter, 2006b). A work system snapshot is a one-page summary of a work system that identifies the main components of six central elements of the work system framework as defined in Table 1, viz., customers, products and services, processes and activities, participants, information, and technologies. Table 4 shows a work system snapshot produced by one of the freshman student teams whose submissions we examine in this paper. At the beginning of the analysis of a work system, the work system snapshot helps in clarifying the scope of the work system and identifying the most important things that it produces for its customers. A more detailed view may then drill down by explaining specifics about each of the snapshot elements in a particular situation. Other tools that are useful in analyzing work systems can be applied as the analysis proceeds.

\section{Table 4: Sample Work System Snapshot of an intercampus book transfer work system, produced by college freshmen}

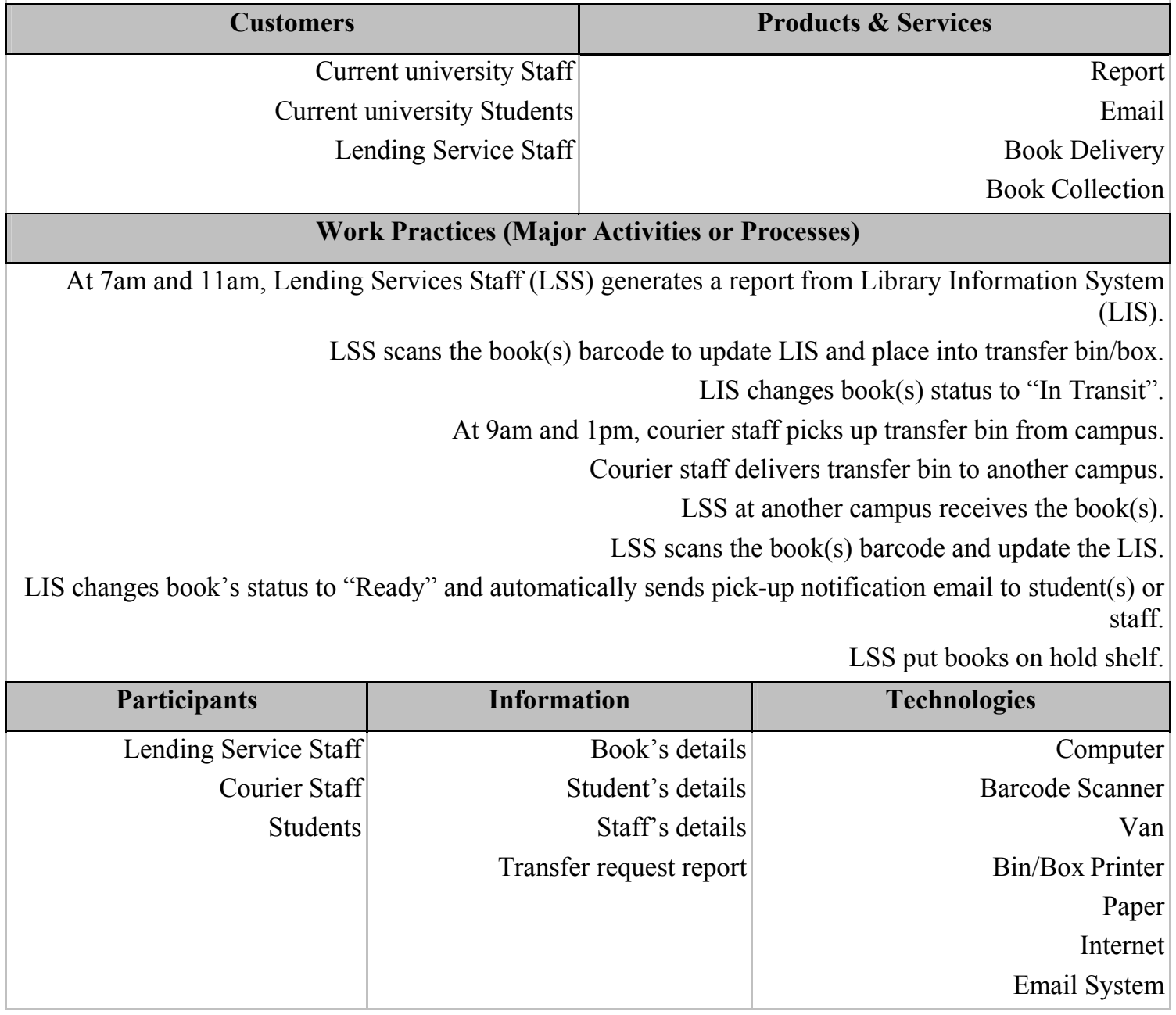


Notice in Table 4 how freshmen were able to produce a work system snapshot that is understandable and clear enough that it can serve as a basis for further analysis that would look at the elements in more detail, perhaps by using flow charts, anecdotes, and data related to work system performance.

\section{Introduction to the Teaching Setting}

The introductory Information Systems course we examine in this paper is a freshman course offered at Queensland University of Technology in Australia. This course is available both as a mandated course within the Bachelor of Corporate Systems Management degree and as an elective course for business and IT students with a major in Corporate Systems Management. The course's goal is to introduce freshman students broadly to the field of Information Systems. To that end, the course gives a broad overview of the nature and role of socio-technical information systems in corporate business settings and of the role that corporate systems managers perform within the major business domains in which they operate.

The course is taught regularly in the first semester of each academic year and attracts between 120 and 190 students overall. More than half of the students come from other countries and bring forth different educational backgrounds. Most students are full time students; around 5 to 10 are part-time students who work as business, system, or process analysts in consulting companies or the corporate business or IT departments of large corporations. Given our focus on the performance of college freshmen, we excluded the (small) percentage of students with business background or working experience. Thus, our research covers a much younger and less experienced student population than was covered in previous pedagogical research involving post-graduate students and upper level undergraduates (Alter, 2006a; Petkov \& Petkova, 2008, 2010; Truex et al., 2010).

The course teaches topics relevant to information systems and their management, consistent with current guidelines for IS teaching curricula (Firth et al., 2008; Ives et al., 2002). The course comprises the following four content blocks. For three of these four blocks, the standard textbook by Kenneth and Jane Laudon ("Management Information Systems: Managing the Digital Firm, 9th edition") was used.

1. Basic concepts and fundamentals of corporate information systems.

2. The role and challenge of corporate information systems management.

3. Different types of corporate information systems for key organizational tasks.

4. Recent trends and future developments in corporate information systems.

In this paper we look at block 2, where the Work System Method was introduced as an approach for communicating, describing, analyzing, and improving IT-reliant systems from a managerial perspective. This block spanned three out of thirteen lecture weeks (weeks 4-6), with each lecture week comprising a 2-hour lecture and a 1-hour tutorial. Overall instruction time pertaining to the work system method was nine hours.

The student reports we examine in this paper are part of an assignment due in week 12 of the course. The assignment officially started in week 6 , allowing the students overall eight weeks for completion (seven lecture weeks plus a mid-semester break of one week length). The assignment was worth $30 \%$ of the final mark in the course, with a further $30 \%$ ascribed to the first assignment, and the final written exam being worth the remaining $40 \%$.

This assignment set out to increase students' awareness of the nature and role of corporate systems and the challenges related to their management in terms of communication, analysis and improvement. Students were asked to investigate the challenges of managing corporate informa- 
tion systems through an assignment using the simplified version of the Work System Method as described in Table 3.

The assignment task for the student was defined as follows.

In groups of four to six participants, students were asked to identify the case of an information system in use within a work system of a corporate organization. Students were free to select the case and were advised that such cases can be found described in computer or business magazines, or through students' work or prior experiences. Students were also allowed to use the case of the information system presented in a previous assignment. Students were informed to look for information about the corporate organization on the Web to gain further insight into the company and prepare a brief description of the business.

The students' task was to analyze the role and use of the selected work system within the corporate organization by taking a Work System View on the selected information system, the work system in which it is used, and the corporate organization. Specifically, students were asked to perform the following steps:

1. Review the case and summarize the work system. Produce a Work System Snapshot (see template provided) so that you can answer the following questions:

a) Identify the main customers of the work system.

b) Identify the main participants in the system.

c) Identify the products or services produced by the system.

d) Summarize the main relevant work practices in the system.

e) Identify the information used and created by the system.

f) Identify the technology used by the system.

g) Identify those aspects of the surrounding environment, strategy and infrastructure that are relevant to the system.

2. Analyze the work system in greater detail, using the Work System Method. Perform an analysis using levels one (headings) and two (questions), and using Steps one (system and problem) and two (analysis and possibilities) of the Work System Method.

Students were asked to produce a written report detailing their findings from tasks 1 and 2 and to provide conclusions derived from the analysis. These conclusions could, but did not have to, include recommendations to the organization for further action.

In the report, the analysis was to be complemented by an introduction to the case organization and the work system selected, information about the work system method as an approach to describe and analyze information systems in corporate organizations, and an executive summary describing the most important results. Appendix A shows the assignment task and shows a sample report template provided to the students.

\section{Student Results}

In this section we examine differences between report examples selected from 20 reports from student teams to identify challenges in applying the work system method faced by undergraduate student teams. Table 5 provides an overview of the student reports received by summarizing selected student team topics and their findings. 
Table 5: Main Conclusions in Selected Student Analyses of Work Systems

\begin{tabular}{|c|c|}
\hline Selected work system & Selected analysis findings \\
\hline $\begin{array}{r}\text { Inter Campus Book } \\
\text { Transfer System }\end{array}$ & $\begin{array}{l}\text { The unclear status of the books being transferred between different campuses of the } \\
\text { university makes it more difficult for a book's requestor to figure out whether or not } \\
\text { the book has arrived at his/her campus. Steps toward a more effective and efficient } \\
\text { work system include simple modifications such as enhancing the clarity of terminol- } \\
\text { ogy about a book's status throughout the work system, and providing easier and } \\
\text { more visually oriented explanatory materials (e.g., process models or similar dia- } \\
\text { grams) for the information system used in the work system. }\end{array}$ \\
\hline Roadside assistance & $\begin{array}{l}\text { Strengths of the system are the award-winning service by Customer Care Assistants } \\
\text { and straightforward structure of the work system, with appropriate procedures for } \\
\text { role allocation and resource utilization. The work system's limitations and con- } \\
\text { straints include the existing infrastructure and absence of GPS in insured cars. } \\
\text { Weaknesses include inefficiency of the supporting information system, interdepen- } \\
\text { dency of software modules within that system, and a rigid relationship to the infor- } \\
\text { mation system's processes that could affect the performance of the work system as a } \\
\text { whole. }\end{array}$ \\
\hline Express E-ship System & $\begin{array}{r}\text { Maintaining the infrastructure of this work system is expensive due to the high fixed } \\
\text { costs. }\end{array}$ \\
\hline $\begin{array}{r}\text { Grocery Store Inven- } \\
\text { tory Management Sys- } \\
\text { tem }\end{array}$ & $\begin{array}{r}\text { Consumers are often confused with the complexity of the current work systems of } \\
\text { package delivery, where they have difficulties in registering, and the tracking of the } \\
\text { packages. Recommendations for system include improved training, streamlined work } \\
\text { processes, and more user-friendly interfaces. }\end{array}$ \\
\hline $\begin{array}{l}\text { Flight Slot Manage- } \\
\text { ment System for an } \\
\text { international airport }\end{array}$ & $\begin{array}{l}\text { Customers' main concern is the reliable availability of the products that they want to } \\
\text { purchase. The work practices that are in place currently succeed in assuring that all } \\
\text { products are of a high standard. Factors that impede work system success include } \\
\text { inefficiencies of RFID guns and monetary and time constraints (e.g., order value } \\
\text { limits, time-to-order limits). }\end{array}$ \\
\hline Flight Booking System & $\begin{array}{l}\text { Problems include a decrease of skilled staff, which increases human errors in per- } \\
\text { forming work within the work system. Recommendations related to automating } \\
\text { methods within the work system would affect the way that flight slot requests are } \\
\text { dealt with, and how older information should be handled and stored for controlling } \\
\text { and management information purposes. The customers who will be affected include } \\
\text { Air Traffic Controllers, Flight Management Staff, Airport Management and the Civil } \\
\text { Aviation Safety Authority. }\end{array}$ \\
\hline
\end{tabular}

In the following, we briefly review selected student papers to uncover the factors distinguishing successful from less successful reports and to identify major types of challenges that undergraduates faced when trying to analyze IT-reliant work systems. Students were informed that electronic copies would be kept. Examples presented in this paper are disguised where required.

We identified successful, average, and unsuccessful reports on basis of a marking criteria sheet that assigned a score of 0-30 marks for each report. We provide the assessment sheet in Appendix B. For the purpose of the analysis reported in this paper, we reviewed marks achieved in the core report sections "Work System Snapshot" and "Work System Method" and also considered the commentary by the teaching personnel marking the reports. Based on this data, we clustered the reports into the three classes, successful, average, and unsuccessful reports, as discussed next. 


\section{Examples of Successful Reports}

\section{Inter Campus Book Transfer System}

The work system that transfers books between campuses of the university was somewhat familiar to the members of the student team. The paper presented an understandable work system snapshot and identified three significant problems with the existing work system (ambiguous status descriptions for books, inappropriate privileges, human errors). Although not required as per assignment instructions, the paper also recommended two work system changes that would ameliorate those problems (first, enhance the clarity of terminology related to a book's status throughout all processes within the work system; second, provide easier, perhaps diagrammatic, explanatory materials to the online information system used within the work system).

One reason for the success of this student paper was that the work system was relatively circumscribed and its work system practices involved participants and objectives that were relatively easy to understand. The more complicated a work system is, and the less familiar it is, the more difficult it is for students to visualize the system and perform an analysis.

\section{Roadside Assistance}

The work system provides roadside assistance to motorists who use mobile phones to contact a call center when a roadside incident occurs. Once again, the function of the work system was relatively circumscribed and could be summarized clearly using a work system snapshot. The team identified constraints (the existing infrastructure and absence of GPS in insured cars), strengths (award-winning service by Customer Care Assistants, the system's straightforward structure, and appropriate allocation of roles), as well as weaknesses (inefficiency of the information system, non-transparent interdependency of its modules, and its rigid relation to the work system's processes and other work practices).

The student team recommended improvements to the user - interface of the information system, improvements in workflow efficiency, a review of the current work system overall to ensure its sustainability for future growth, and new business models (e.g., membership packages) related to the work system. This paper's success could have been due in part to notable extra efforts to conduct additional, detailed analyses, such as trying to identify measurable organizational value of the work system.

\section{Examples of Average Reports}

\section{Dell Computer}

A paper about Dell Computer was generally successful in demonstrating that the freshman team authors understood that Dell Computer operates through processes such as ordering inventory, accepting orders, and assembling computers. However, the paper revealed confusion about relationships between work systems containing those processes. For example, the first step in the paper's work system snapshot is that the customer sends an order to Dell. The next step is that Dell sends orders to its suppliers. A more accurate summary is that Dell decides what computers it wants to sell, orders the required components, and then uses those components to build computers within a few days of receiving customer orders. It is possible that the students who wrote this paper might have been able to learn more about how Dell's value chain operates. The student paper cited privacy as the main issue for this work system. More thorough research about Dell probably would have identified other issues, or possibly opportunities related to improving efficiencies or enhancing product offerings. Nonetheless, the student paper revealed a relatively satisfactory understanding of Dell for students who are freshmen. It seemed likely that their research would help 
them understand many other corporate examples that they would encounter later in their coursework and careers, even though this first report revealed a number of problems. Those problems included including difficulties in describing the work system examined and difficulties in drawing correct conclusions from a thorough analysis of the elements involved.

\section{Grocery Store Inventory Management System}

The team identified major steps within an inventory management at a local grocery store (e.g., ordering, product placement, and stock calculations) and identified capabilities within information systems (e.g., an order management system) and technologies (e.g., RFID guns). The work system snapshot identified sets of work system participants (e.g., management personnel, store staff, delivery personnel).

The recommendations were the main area of concern for this team. Although it made recommendations (e.g., a web-based information system for order management, better algorithms for stock calculations), it struggled in identifying which steps specifically could benefit from the use of an upgraded order management information system and how products and practices would change in an improved IT-reliant work system. The analysis of the work system's fit to the organization's environment had other shortcomings. Important processes and IT interfaces were neither identified nor examined by the students, so that no recommendations could be made as to how to improve the overall position of the work system in the inter-organizational supply chain of the grocery store and its suppliers.

\section{Examples of Unsuccessful Reports}

\section{Large Retailer}

The student team obtained information about a large retailer, yet failed to identify any clearly defined work system within the organization. They cited a number of facts that were related to topics in the course, but did not present those facts in a way that led to meaningful, justified conclusions. Their work system snapshot revealed confusion about what a work system is and what activities and processes mean in the context of a work system. Their paper revealed difficulties in identifying the work system, such as misunderstandings about activities and processes in the context of a work system. Their work system snapshot included statements that did not belong in a work system snapshot, such as "a customer expects good customer service from a company," "several other departments' officers and heads use computers and IT extensively whereas other may use little or no technology," and "an additional benefit now includes subsidized catering facilities." Similarly, the students failed to identify the set of products and services generated through the work system (the products/services named by the students included "Plan A" and "Customer Cheque \& invoices"). The inadequate identification of the work system and its constituent elements made it difficult for the students to perform a meaningful analysis and, therefore, to provide justifiable recommendations.

\section{Ebay}

The student team failed to report specifically on any work system within the eBay organization and, instead, offered statements about the organization in general. Students studying eBay using the work system approach could potentially consider the auction system as the work system. That work system would probably start when a seller creates an auction and would end when an auction ends with a winning bid or when the buyer pays for the item or receives it. Inspection of the student report revealed a misplaced focus on describing the work system method rather than the work system being studied. In other words, the students misunderstood the assignment. 


\section{Challenges for Students}

The assignments submitted by freshman student teams revealed a number of difficulties and confusions, of which the following occurred at least several times:

A number of papers revealed confusions about basic WSM terms and concepts. For example, one paper contained the following statement, "A Work System Method has been modeled to derive a clear understanding of the business and its processes." Another paper said, "This report sets out to establish and analyze the Work System Method." These teams and several others did not fully understand that WSM is a method of analyzing a system in an organization and that a work system model starts with the work system snapshot. They were confused about the difference between the method, the snapshot, and the underlying concepts. Several similar examples in less successful papers illustrate the need to make sure that terminology and abstractions are welldefined and carefully discussed in class.

A number of papers revealed confusion between work systems and information systems. The goal of the work system method is to improve the work system. Those improvements may include improvements to the information system and/or improvements to parts of the work system that do not touch the information system. The latter distinction is a bit subtle for undergraduates in the context of an introductory information system course. It is noteworthy, however, that this distinction is sometimes overlooked even in the larger context of the IS field, which often does not distinguish clearly between work system improvements that result directly from information system changes and other work system improvements that may have happened at the same time but were not directly related to the information system changes.

A number of papers revealed confusion about the scope of the analysis. Some of the less successful reports (e.g., eBay) and even some of the moderately successful reports (e.g., Dell) had problems in defining the focus of the analysis. A scope-related problem in some of the reports was that a team considered organizations that operated on an e-commerce business model (e.g., eBay, Amazon, Facebook) to be a single work system, instead of identifying specific work systems within these organizations (e.g., an auction work system or a book ordering system). In these cases, there was some confusion between organizations whose business models are enabled through information systems and specific work systems that rely on information systems.

A number of papers revealed inadequate critical thinking. We identified a number of occurrences of inadequate critical thinking (R. W. Paul \& Elder, 2002) in the student reports, in some cases similar to challenges faced by postgraduate students when analyzing IT-reliant work systems (Alter, 2006a). Such problems were revealed in confused understandings of important IS concepts, difficulty in presenting and applying evidence, or poorly justified recommendations. Of the ten common problems related to critical thinking identified by Alter (2006a), we found shortcomings related to the following aspects of critical thinking:

- Defining the problem (clarifying scope, limits, and essence of the problem)

- Gathering information and evidence (arguing on the basis of relevant information rather than on the basis of unsupported opinions)

- Drawing inferences and interpretations (interpreting information appropriately)

- Searching for alternatives (identifying possibilities and clarifying the range of options)

- Drawing conclusions (offering recommendations that are supported by evidence or analysis)

- Presenting a coherent and complete argument (explaining relevant facts and findings) 


\section{Student Feedback}

We gathered preliminary evidence for the perceived effectiveness of the Work System Method as a teaching tool in an undergraduate IS course by examining qualitative responses from the formal unit evaluation data gathered at Queensland University of Technology in 2009 when WSM was introduced into the course.

At Queensland University of Technology, students are asked for anonymous feedback at the end of every semester through a standardized online feedback form. This form asks the students to assess relevance, difficulty, workload, assessment and relevance of the content as well as the delivery of the teaching through the instructors through a 5-point scale. Additionally, and for our purposes more importantly, the evaluation mechanism also allows students to comment freely on the various aspects of the course, including the assessments.

Inspecting the qualitative feedback from the student comments relating to the WSM assignment, we find that the inclusion of the WSM assignment was perceived as mostly positive, as illustrated by the following comments:

- The group assessments allowed me to relate the subject to a real life situation that might happen to me in future.

- We learn more about the work systems within a business/company, which lets us understand more about how the business works.

- You get to know more about IT, what systems are made of IT how they are related to the organizations.

- $\quad$ The Work System Method is a great tool that can be applied to any organization. [The assignment] sparked interest in information systems application to industry.

- Learning about business aspects, this gives a good insight in the workings of IT systems in different businesses.

These and other similar comments indicate student recognition that WSM helps in understanding how information systems contribute to business practice.

Recognition of the practical relevance of the approach also became evident from the comments. Specifically, some students found that the work system method allowed for a close integration between theoretical content and their practical application in their day-to-day jobs:

- The best thing I found was that I was able to apply my existing knowledge of work systems and corporate information systems, gained from working in business for 6 years, to the course content. My group did both assignments on scenarios from my current workplace. I found it great that we were able to do this, as it improved my understanding both of the course content and also of my job.

Regarding disadvantages of the WSM, some of the feedback received pointed to the large amount and complexity of the work required ("Group assessments were too complicated." "Too much work and group work."). Notably, the business focus on information systems provided by the WSM was also seen as a challenge by some students: "As not taking a business course, it's kind of hard to blend in during lectures; the material is talking deep inside a business." Especially for freshmen students with little to no work experience, it was felt that some parts of the WSM approach were challenging to comprehend:

- I could apply knowledge I have gained from working with information systems in corporate organizations. However it felt like the work system method was catered more to my level (that is, students who already had some understanding of the topic through work) rather than at the level of some of my friends (no experience working in business, and found it difficult to relate to some of the content). 
We recognize the difference between collecting student feedback versus collecting rigorous data on learning outcomes. Nonetheless, a large share of student comments about the inclusion of WSM as a part of the course was positive. While not discussed here in detail, the overall course ratings, too, were significantly improved on previous years, which seems to indicate that inclusion of a major project based on WSM contributed to improvements in the units across all evaluation criteria. Of course, we recognize that other factors such as experience, change of teaching team, and/or improved teaching skills will also have contributed to the improvement of the course.

\section{Implications for Teaching}

The successes and difficulties that we observed lead to a number of implications for presenting work system concepts and using them in major class assignments for undergraduates with no or little business experience. We summarize these implications in the following recommendations:

Be clear about the assignment. Although most students understood that they were supposed to use work system ideas to perform an overview level analysis of a work system in an organization, several student teams believed they were supposed to describe the possible relevance of a work system approach to a specific situation. A straightforward way to address this type of issue is to provide examples of effective and ineffective analysis and to provide appropriate templates that will guide the student analysis effort.

Provide examples showing effective and ineffective analysis. One of the ways to guide student assignments is to preempt mistakes they might make by showing examples of effective and ineffective work. A good example is the difference between effective and ineffective work system snapshots. Table 4 presented an example of a good work system snapshot produced by a student team. In contrast, Table 6 shows an ineffective work system snapshot.

Table 6: Example of an ineffective work system snapshot (Alter, 2009)

\begin{tabular}{|r|r|r|}
\hline \multicolumn{2}{|c|}{ Customers } & Products \& Services \\
\hline \multicolumn{2}{|r|}{ Applicant } & Loan \\
\hline \multicolumn{3}{|r|}{ Work Practices (Major Activities or Processes) } \\
\hline \\
\hline
\end{tabular}

Notice how Table 6 provides so little information that many important topics are unclear, such as who performs which activities, what information they really use, whether this system actually produces a loan or something else, and whether this work system has customers other than the loan applicant.

Provide templates for analyzing a work system. Another way to help students write good papers and to help them learn work system concepts is to provide templates for analyzing a work 
system. Potential templates include a fill-in-the-blanks section for identifying major problems or opportunities and constraints, a blank table for identify important metrics for the work system along with important performance gaps, and a blank work system snapshot for summarizing the work system under analysis. Truex et al. (2010) report on using this type of approach successfully with advanced MBA students.

Clarify terminology. Some of the student papers revealed confusion about basic terminology and concepts. Here are some of the clarifications that would have helped, and which could be provided in the form of a terminology or dictionary handout:

- Work system: A system in which human participants and/or machines perform work (processes and activities) using information, technology, and other resources to produce specific products and/or services for specific internal or external customers.

- Work system framework: A framework identifying nine elements that inform a basic understanding of a specific work system.

- Work system snapshot: A one-page summary of a specific work system in terms for six elements: customers, products and services, processes and activities, participants, information, and technologies.

- Work system method: A systems analysis method that uses work system ideas for understanding and analyzing systems in organizations. The work system method uses the work system snapshot and many other concepts and tools.

The terms in the work system framework should also be defined carefully. For example, customers receive and use products and services that the work system produces for purposes other than doing work within the work system itself. Customers may be work system participants (as in selfservice with ecommerce), but work system participants need not be work system customers.

Provide familiar examples of work systems. A good way to introduce work system concepts is to ask students to produce work system snapshots of work systems they are familiar with, such as how a video store works, how a library works, or how university registration works. One approach is to ask each student to produce a work system snapshot of a familiar work system and to bring three copies of it to class. In class, students work in teams of three, with each student passing his/her work system snapshot to the other two teammates. Without any help from the author of the work system snapshot, a student who receives a work system snapshot should read it quickly and then try to explain that work system to the other two students. It soon becomes clear that a good work system snapshot with an adequate amount of clearly stated information is a good summary of a work system, and that incomplete or sloppy work system snapshots are difficult to understand. Through a debrief after this exercise, the lecturer can reinforce issues such as what each work system snapshot really means and indications of whether a work system snapshot is good or not.

Emphasize the difference between a technology, a work system, and an organization. A number of student teams were confused about whether they were to analyze a work system within an organization or whether the organization was a work system (e.g., the eBay example mentioned earlier). Although it is possible to think of an entire organization or enterprise as a single work system, usually that is not useful for analysis because an entire enterprise typically comprises a large number of work systems and contains too many people in different roles performing too many different activities. Simply using a set of examples to illustrate the difference should suffice in making this point. Other students were confused about whether they were supposed to report on technologies that were used or on how technologies enabled the operation of work systems.

Treat the scope of any work system as a choice, not a given. Students should realize that the scope of a work system depends on the problem or opportunity that is being analyzed. The gen- 
eral rule of thumb is that the work system is the smallest work system that has the problem or opportunity that is being studied. That rule of thumb is reasonably effective when business professionals use a work system approach for thinking about business problems and issues. It may be less effective when undergraduate students use work system concepts to describe business situations that they learn about through secondary sources.

Be sure that students analyze appropriate work systems. Ideally students should analyze work systems to which they have some access though a job, friend, or family member. Student teams can be formed around such opportunities, since some students will not have the appropriate contacts. It is also possible to form student teams around topics that can be researched through secondary sources such as magazines, newspapers, and corporate information that can be found using Internet search engines. Table 7 is part of a list of work systems that one of the authors has provided to student teams that lack personal access to an appropriate real world system. Further information about these and other work systems is sometimes available in major newspapers, published case studies, IT-related periodicals such as CIO Magazine, CIO Insight, InformationWeek, Baseline, and Computerworld, and business periodicals such as Bloomberg BusinessWeek, Fortune, Forbes, and Fast Company.

Regardless of whether information about the work system is obtained through primary or secondary sources, it is useful to check that students are analyzing appropriate work systems. This can be done by asking that students submit a work system snapshot and a brief summary of the problem or opportunity soon after they start the project and well before it is due.

\section{Table 7: Possible Work System Topics for Student Reports Based on Secondary Sources}

\begin{tabular}{|c|c|c|}
\hline Examples & Examples (ctd.) & Examples (ctd.) \\
\hline $\begin{array}{r}\text { Billing in law firms or other } \\
\text { professional service firms }\end{array}$ & Producing animated movies & $\begin{array}{r}\text { Compliance with Sarbanes Oxley } \\
\text { legislation (reducing costs) }\end{array}$ \\
\hline FBI's Virtual case file & Controlling traffic & $\begin{array}{r}\text { ChoicePoint }- \text { controlling access to } \\
\text { information }\end{array}$ \\
\hline Air traffic control & Moving packages (FedEx, UPS) & Insurance sales systems \\
\hline IRS information system & Virtual office & Agile software development \\
\hline Trading in stocks or bonds & Industrial sales systems & $\begin{array}{r}\text { Taking orders for a new cell phone } \\
\text { or land line }\end{array}$ \\
\hline FBI's Virtual case file & $\begin{array}{r}\text { Use of CAD (computer aided de- } \\
\text { sign) in surgery }\end{array}$ & Netflix \\
\hline $\begin{array}{r}\text { Controlling commercial air- } \\
\text { plane flights }\end{array}$ & Electronic medical records & $\begin{array}{r}\text { Order fulfillment at Zappos.com } \\
\text { (or other interesting ecommerce } \\
\text { site) }\end{array}$ \\
\hline Vendor managed inventory & Customs clearance for ports & Supply chain in clothes retailing \\
\hline $\begin{array}{r}\text { Reordering in grocery stores or } \\
\text { department stores }\end{array}$ & $\begin{array}{r}\text { Boeing's supply chain and supply } \\
\text { chain issues for its new Dreamliner } \\
\text { airplane }\end{array}$ & $\begin{array}{r}\text { Kaiser Permanente's new medical } \\
\text { records system }\end{array}$ \\
\hline $\begin{array}{l}\text { Risk control systems in a large } \\
\text { investment bank or brokerage }\end{array}$ & $\begin{array}{r}\text { Payment Card Industry Data Secu- } \\
\text { rity Standard - how and how well it } \\
\text { operates }\end{array}$ & Voting systems \\
\hline Airline passenger screening & Managing call centers & $\begin{array}{r}\text { Financial planning process at a } \\
\text { large company }\end{array}$ \\
\hline $\begin{array}{r}\text { Billing battles related to health } \\
\text { claims }\end{array}$ & $\begin{array}{r}\text { Entering and fulfilling orders in } \\
\text { restaurants }\end{array}$ & RFID at Wal-Mart \\
\hline
\end{tabular}


Recognize limitations related to student background and interest. A work system assignment in a freshman course should be viewed as a starting point for novice level understanding that will improve over time with subsequent work and study experiences. The common lack of business experience makes it more difficult for most undergraduate students, and especially freshmen, to appreciate the significance and meaning of information systems and their support of work systems in organizations. Although understanding work systems is challenging in the same way, at least the relationship between work system performance and business performance is more direct and easier to visualize. For example, it is reasonably straightforward that outstanding performance by a firm's manufacturing or sales work systems tends to generate high levels of efficiency and revenue. The work system assignment helps students understand that organizations operate through work systems and that IT and information systems play a crucial role in work system performance.

\section{Conclusion}

The goal of an introductory information systems course is to provide the understandings needed by IS students as well as those students majoring in IS as part of their business or IT degree (Firth et al., 2008). This paper discussed experiences using the Work System Method for teaching freshmen students about the management of information systems in business settings, with a focus on their ability to identify, analyze, improve, and communicate about the role of information systems in organizational work systems.

We described the lessons and challenges with using this approach in teaching freshmen. Our recommendations for using WSM effectively with freshmen can be summarized as follows:

- Provide greater clarity about basic ideas about work systems and the analysis of work systems,

- Provide examples that illustrate effective vs. ineffective work system snapshots,

- Help students find appropriate examples of work systems (such as the ones provided in Table 2 or Table 7), and

- Provide early feedback about whether student teams are studying work systems that are sufficiently focused.

We conclude that the work system approach can help freshmen and other undergraduates develop an understanding of some of the fundamental relationships between work systems, information systems, and IT. Our experience with freshmen students indicates that the work system method is a suitable pedagogical tool for introducing inexperienced undergraduate students to information systems, their role in organizations, and the challenges related to their management.

Our work has limitations. This paper reports on the application of the WSM in the context of only one university. The effects on student performance and satisfaction may not transfer to student cohorts in other institutions. We used student feedback on teaching quality as an indication of the success of this approach. Future work could examine impacts on learning performance under conditions different from those reported in this paper.

\section{References}

Abraham, T., Beath, C. M., Bullen, C. V., Gallagher, K., Goles, T., Kaiser, K., et al. (2006). IT workforce trends: Implications for IS programs. Communications of the Association for Information Systems, 17(50), 1147-1170.

Albrecht, C. C., Romney, M., Lowry, P. B., \& Moody, G. (2009). The IS core: An integration of the core IS courses. Journal of Information Systems Education, 20(4), 451-468. 
Alter, S. (2003). 18 reasons why IT-reliant work systems should replace "The IT Artifact" as the core subject matter of the IS field. Communications of the Association for Information Systems, 12(23), 366395.

Alter, S. (2006a). Pitfalls in analyzing systems in organizations. Journal of Information Systems Education, 17(3), 295-302.

Alter, S. (2006b). The work system method: Connecting people, processes, and IT for business results. Larkspur, California: Work System Press.

Alter, S. (2007). Could the work system method embrace systems concepts more fully. Information Resource Management Journal, 20(2), 33-43.

Alter, S. (2008). Defining information systems as work systems: Implications for the IS field. European Journal of Information Systems, 17(5), 448-469.

Alter, S. (2009). Example of an ineffective work system snapshot. Teaching materials for MBA-6113. San Francisco, California: University of San Francisco.

Bullen, C. V., Abraham, T., Gallagher, K., Simon, J. C., \& Zwieg, P. (2009). IT workforce trends: Implications for curriculum and hiring. Communications of the Association for Information Systems, 24(9), 129-140.

Carlsson, S. A., Hedman, J., \& Steen, O. (2010). Integrated curriculum for a bachelor of science in business information systems design (BISD 2010). Communications of the Association for Information Systems, 26(24), 525-546.

Firth, D., Lawrence, C., \& Looney, C. A. (2008). Addressing the IS enrollment crisis: A 12-step program to bring about change through the introductory IS course. Communications of the Association for Information Systems, 23(2), 17-36.

Helfert, M. (2008). Business Informatics: An engineering perspective on information systems. Journal of Information Technology Education: Research, 7, 223-245. Retrieved from http://www.jite.org/documents/Vol7/JITEv7p223-245Helfert354.pdf

Hoffer, J. A., George, J. F., \& Valacich, J. S. (2007). Modern systems analysis and design (5th ed.). Upper Saddle River, New Jersey: Prentice Hall.

Hunsinger, D. S., \& Smith, M. A. (2008). Factors that influence information systems undergraduates to pursue IT certification. Journal of Information Technology Education: Research, 7, 247-265. Retrieved from http://www.jite.org/documents/Vol7/JITEv7p247-265Hunsinger360.pdf

Ives, B., Valacich, J., Watson, R. T., Zmud, R. W., Alavi, M., Baskerville, R., et al. (2002). What every business student needs to know about information systems. Communications of the Association for Information Systems, 9, 467-477.

Kamoun, F., \& Selim, S. (2007). A framework towards assessing the merits of inviting IT Professionals to the classroom. Journal of Information Technology Education: Research, 6, 81-103. Retrieved from http://www.jite.org/documents/Vol6/JITEv6p081-103Kamoun223.pdf

Luftman, J., \& Zadeh, H. S. (2011). Key information technology and management issues 2010-11: An international study. Journal of Information Technology, 26(3), 193-204.

Miliszewska, I., Venables, A., \& Tan, G. (2010). Didactics of information technology (IT) in a science degree: Conceptual issues and practical application. Journal of Information Technology Education: Innovations in Practice, 9, 79-89. Retrieved from http://www.jite.org/documents/Vol9/JITEv9IIPp079089Miliszewska826.pdf

Murray, M. C. (2010). Database security: What students need to know. Journal of Information Technology Education: Innovations in Practice, 9, 61-77. Retrieved from http://www.jite.org/documents/Vol9/JITEv9IIPp061-077Murray804.pdf

Paul, R. J. (2010). Loose change. European Journal of Information Systems, 19(4), 379-381. 
Paul, R. W., \& Elder, L. (2002). Critical thinking: Tools for taking charge of your professional and personal life. Upper Saddle River, New Jersey: Prentice Hall.

Petkov, D., \& Petkova, O. (2006). Development of scoring rubrics for IS projects as an assessment tool. Issues in Informing Science and Information Technology, 3, 499-510. Retrieved from

Petkov, D., \& Petkova, O. (2008). The work system model as a tool for understanding the problem in an introductory IS project. Information Systems Education Journal, 6(21), 3-12.

Petkov, D., \& Petkova, O. (2010). An exploratory study on the student acceptance of the work system method as part of the systems analysis and design course. Paper presented at the 27th Information Systems Educator Conference, Nashville, Tennessee.

Petkov, D., Petkova, O., Sewchurran, K., Andrew, T., \& Misra, R. (2012). The work system method as an approach for teaching and researching information systems. In Y. K. Dwivedi, M. R. Wade, \& S. L. Schneberger (Eds.), Information systems theory: Explaining and predicting our digital society, Vol. 2 (pp. 413-424). New York, New York: Springer.

Ramiller, N. C. (2005). Animating the concept of business process in the core course in information systems. Journal of Informatics Education Research, 3(2), 53-71.

Topi, H., Valacich, J. S., Wright, R. T., Kaiser, K., Nunamaker Jr, J. F., Sipior, J. C., et al. (2010). IS 2010: curriculum guidelines for undergraduate degree programs in information systems. Communications of the Association for Information Systems, 26(18), 359-428.

Truex, D. P., Alter, S., \& Long, C. (2010). Systems analysis for everyone else: Empowering business professionals through a systems analysis method that meets their needs. Paper presented at the 18th European Conference on Information Systems, Pretoria, South Africa.

Venables, A., \& Tan, G. (2009). Realizing learning in the workplace in an undergraduate IT program. Journal of Information Technology Education: Innovations in Practice, 8, 17-26. Retrieved from http://www.jite.org/documents/Vol8/JITEV8IIP017-026Venables706.pdf

Zhang, X., \& Olfman, L. (2010). Studios, mini-lectures, project presentations, class blog and wiki: A new approach to teaching web technologies. Journal of Information Technology Education: Innovations in Practice, 9, 187-199. Retrieved from http://www.jite.org/documents/Vol9/JITEv9IIPp187199Zhang813.pdf

\section{Appendix A: Instructions Students Received for Applying a Simplified Version of WSM}

\section{Using the Work System Method, investigate the challenges of managing corporate work sys-} tems

In a group of four to six classmates, identify the case of an information system in use within a work system of a corporate organization. You may find such cases described in computer or business magazines, or through your own work or experiences. It is allowed to use the case of the information system presented in your previous assignment. Look for information about the corporate organization on the Web to gain further insight into the company and prepare a brief description of the business. 
Your task is to analyze the role and use of the selected work system within the corporate organization. Take a Work System View on the selected information system, the work system in which it is used, and the corporate organization, and perform the following steps:

1. Review the case and summarize the work system. Produce a Work System Snapshot (see template provided) so that you can answer the following questions:

a) Identify the main customers of the work system.

b) Identify the main participants in the system.

c) Identify the products or services produced by the system.

d) Summarize the main relevant work practices in the system.

e) Identify the information used and created by the system.

f) Identify the technology used by the system.

g) Identify those aspects of the surrounding environment, strategy and infrastructure that are relevant to the system.

2. Analyze the work system in greater detail, using the Work System Method. Perform an analysis using levels one (headings) and two (questions), and using Steps one (system and problem) and two (analysis and possibilities) of the Work System Method. You will find all relevant instructions and questions to answer in the Work System Method textbook (Alter, 2006b).

Produce a written report detailing your findings. Provide conclusions derived from your analysis. These conclusions may, but do not have to, include recommendations to the organization for further action.

Complement your analysis by an introduction to the case organization and the work system selected, information about the work system method as an approach to describe and analyze information systems in corporate organizations, and an executive summary describing the most important results. Refer to the sample report structure below for guidance.

\section{Sample Report Structure}

The following components should be included in the report:

- Declaration by group members

- Cover page

- Executive summary

- Table of contents

- Introduction (purpose of report, signposting etc.)

- Overview of the Work System Method

- Introduction to the selected case

- Work System Snapshot

- Analysis as per Work System Method

- Conclusion

- References

- Appendix: Any relevant further tables, figures, screenshots 


\section{Appendix B: Student Report Marking Sheet}

\begin{tabular}{|c|c|c|c|c|}
\hline $\begin{array}{l}\text { Assessment } \\
\text { Item }\end{array}$ & Explanation & $\begin{array}{l}\text { Reviewer } \\
\text { Comments }\end{array}$ & \begin{tabular}{|c|} 
Marks \\
available
\end{tabular} & $\begin{array}{c}\text { Marks } \\
\text { achieved }\end{array}$ \\
\hline Introduction & $\begin{array}{l}\text { This part has to provide a well-structured chapter leading into the report. The report has to be moti- } \\
\text { vated by stressing the significance of the topic. An overview about the structure of the report, assump- } \\
\text { tions, etc. has to be provided. }\end{array}$ & & 2 & \\
\hline $\begin{array}{r}\text { Background to } \\
\text { Work System } \\
\text { Method and } \\
\text { Case Organiza- } \\
\text { tion }\end{array}$ & $\begin{array}{l}\text { This part will largely be based on related literature. Provide an overview and introduction of the Work } \\
\text { System Approach. Assume that your reader has no knowledge of this approach. Describe objectives } \\
\text { and assumptions of the approach. Also provide a short, sharp and concise background to the case or- } \\
\text { ganization and the specific business process that is the core of the work system analyzed. Again, ex- } \\
\text { pect readers to be unfamiliar with the domain, and write accordingly. }\end{array}$ & & 3 & \\
\hline $\begin{array}{r}\text { Work System } \\
\text { Snapshot }\end{array}$ & $\begin{array}{l}\text { The work system snapshot should be completed using the template provided, and should appropriately } \\
\text { summarize the key elements of the work system. The snapshot should allow the reader to quickly iden- } \\
\text { tify relevant customers, products/services, work practices, information, technology, participants. }\end{array}$ & & 7 & \\
\hline $\begin{array}{r}\text { Work System } \\
\text { Method }\end{array}$ & $\begin{array}{l}\text { This is the core of the report. Use the headings and questions pertaining to level one and two of the } \\
\text { work system method to comprehensively analyze the selected work system. Provide comprehensive } \\
\text { answers to all level questions (SP1-5 and AP-10). }\end{array}$ & & 10 & \\
\hline Conclusion & $\begin{array}{l}\text { The conclusions should summarize the main findings, contextualize the report and also cover any po- } \\
\text { tential limitations. Identify any lessons learnt and derive main ideas from the analysis, so that the ques- } \\
\text { tion "so what?" can be answered. }\end{array}$ & & 3 & \\
\hline $\begin{array}{r}\text { Language / } \\
\text { Format }\end{array}$ & $\begin{array}{l}\text { The report has to comply to the highest standards in terms of language and grammar. The entire report } \\
\text { format should be adequate and well-designed. Figures, tables and appendices should meaningfully } \\
\text { complement the text. The constraints are: max. } 20 \text { pages, } 12 \mathrm{pt} \mathrm{font} \mathrm{size.}\end{array}$ & & 2 & \\
\hline $\begin{array}{r}\text { Executive } \\
\text { Summary, Ref- } \\
\text { erences, Ap- } \\
\text { pendix }\end{array}$ & $\begin{array}{l}\text { These sections must complement the core of the report. Is their length appropriate? The executive } \\
\text { summary should 'excite' the reader and provide a condensed summary of the main findings (what do } \\
\text { we get from this analysis?), not a simple overview about the structure of the report. The references } \\
\text { should be relevant and integrated into the core of the report. The appendices must be relevant and con- } \\
\text { sistent. }\end{array}$ & & 3 & \\
\hline
\end{tabular}




\section{Biographies}

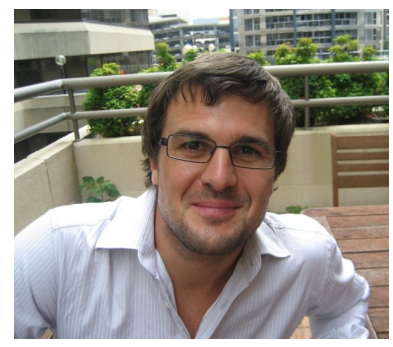

Dr. Jan Recker is Alexander-von-Humboldt Fellow and Associate Professor for Information Systems at Queensland University of Technology, Brisbane, Australia. His main areas of research include usage of process design in organizational practice, IT-enabled business transformations and organizational innovation. His research is published in the MIS Quarterly, the Journal of the Association for Information Systems, Information Systems, the European Journal of Information Systems, Information \& Management, the Scandinavian Journal of Information Systems and others. He is an Associate Editor for the Communications of the AIS, a member of the editorial board of several international journals and serves on the program committee of various conferences.

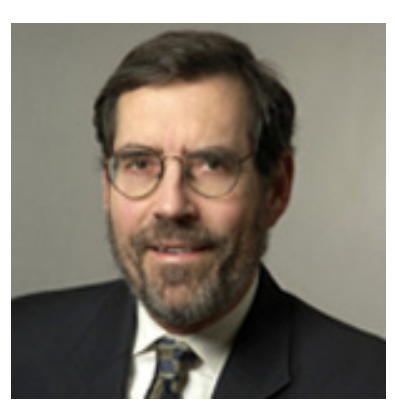

Steven Alter is Professor of Information Systems at the University of San Francisco. He received his B.S. and Ph.D. at MIT. His research for the last decade has concerned developing systems analysis concepts and methods that can be used by typical business professionals and can support communication with IT professionals. His 2006 book, The Work System Method: Connecting People, Processes, and IT for Business Results, is a distillation and extension of ideas in 1992, 1996, 1999, and 2002 editions of his information system textbook. His articles have been published in Harvard Business Review, Sloan Management Review, MIS Quarterly, IBM Systems Journal, European Journal of Information Systems, Decision Support Systems, Interfaces, Communications of the ACM, Communications of the Association for Information Systems, CIO Insight, and many refereed conference proceedings. 